Jurnal Quantum Teknika

Vol. 1, No. 1, Hal 14-18, Oktober 2019

\title{
Pengaruh Tekanan Kompresi Terhadap Daya Dan Torsi Pada Engine Single Piston
}

\author{
Bagiyo Condro Purnomo*, Suroto Munahar \\ Program Studi Mesin Otomotif, Universitas Muhammadiyah Magelang, Indonesia \\ Penulis korespondensi: bagiyo_condro@ummgl.ac.id
}

Histori artikel: diserahkan 23 April 2019, direviu 27 Juni 2019, direvisi 20 Juli 2019

\begin{abstract}
$L P G$ is an alternative fuel as fuel oil (BBM) which has a higher octane and energy value compared to BBM, and produces lower exhaust emissions. However, engine performance has decreased. This research presents an analysis of the performance of a single piston 4-stroke LPG engine with changes in compression pressure. Tests were carried out to determine the power and torque with variable pressure compression of 9 bar, 9.5 bar and 10 bar. The test results show that a single piston 4-stroke LPG engine with 9 Bar compression pressure produces a maximum torque of $9.77 \mathrm{Nm}$ at $3380 \mathrm{rpm}$ and a maximum power of $6.7 \mathrm{HP}$ at $5870 \mathrm{rpm}$. Whereas the 10 Bar compression pressure produces a maximum torque value of $10.79 \mathrm{Nm}$ at $3689 \mathrm{rpm}$ and a maximum power of $6.9 \mathrm{hp}$ at $5936 \mathrm{rpm}$. The conclusion of this research is that the higher the engine compression pressure, the higher the thermal efficiency in the combustion chamber so that engine performance increases

Keywords: LPG, compression pressure, Torque, Power
\end{abstract}

DOI: $10.18196 /$ jqt.010103

Web: http://journal.umy.ac.id/index.php/qt

\section{PENDAHULUAN}

Perkembangan teknologi transportasi sebanding dengan jumlah kendaaraan saat ini, hal tersebut dapat dilihat pada data Badan Pusat Statistik Indonesia tahun 2013 dimana pertambahan jumlah kendaraan mencapai 104.118.969 unit. Namun hal tersebut tidak sesuai dengan ketersediaan bahan bakar sehingga memicu kenaikan harga BBM yang berdampak pada perekonomian masyarakat. Penggunaan BBM akan memberikan peningkatan polusi udara sehingga akan merusak lingkungan dan menurunkan tingkat kesehatan manusia, sehingga bahan bakar LPG menjadi alternative Liquefied petroleum gas (LPG) (Ashok et al., 2015).

LPG diproduksi bersamaan dengan produksi gas alam. Unsur kimia LPG berasal dari unsur propana atau butana, ataupun campuran propana $\left(\mathrm{C}_{3} \mathrm{H}_{8}\right)$ dan butana $\left(\mathrm{C}_{4} \mathrm{H}_{10}\right)$ serta terdapat dalam konsentrasi kecil propilen dan butilena. Sebagai bahan aroma atau bau sehingga dapat mendeteksi kebocoran ditambahkan ethyl mercaptan (Y \& R, 2013). Umumnya disimpan dalam silinder sebagai cairan pada tekanan dalam kisaran 10-15 bar yang menghilangkan kebutuhan pompa umpan bahan bakar (Ravi et al., 2017).

Sebagai bahan bakar alternatif LPG mempunyai nilai oktan yang tinggi yaitu 112 sangat baik untuk jenis mesin bensin (spark ignited) (Pourkhesalian, Shamekhi, \& Salimi, 2010). Disamping itu LPG mempunyai energy content sebesar 46,4 $\mathrm{MJ} / \mathrm{kg}$, sedangkan kandungan energi bensin sebesar $44.4 \mathrm{MJ} / \mathrm{kg}$ atau 34,8 $\mathrm{MJ} / \mathrm{l}$. Disamping itu, LPG memiliki kandungan energi per satuan massa relatif tinggi, tetapi kandungan energi per satuan volumenya rendah (Pourkhesalian et al., 2010), (Purnomo, et al., 2017), (ETSAP, 2010).

Nilai oktan yang tinggi memungkinkan untuk diterapkan pada mesin-mesin dengan rasio kompresi tinggi, yang dapat memberikan peningkatan efisiensi termal yang lebih baik, mengurangi konsumsi bahan bakar, dan mereduksi emisi gas buang (Saraf, Thipse, \& Saxena, 2009). Disamping itu penggunaan bahan bakar LPG memiliki efek pada lingkungan yang lebih baik daripada penggunaan bahan bakar bensin, untuk semua 
kadar emisi $\mathrm{CO}, \mathrm{CO}_{2}, \mathrm{HC}$, dan NOx (Bayraktar \& Durgun, 2005) (Pradesh-india \& Pradeshindia, 2008), (Pourkhesalian et al., 2010).

Penggunaan LPG menghasilkan performa kurang baik dibandingkan gasoline. Penurunan daya yang terjadi pada umumnya berkisar antara 5\% sampai 20\% (Ceviz \& Yu, 2006) (Ceviz \& Yu, 2006). Disamping itu, penggunaan LPG mengurangi konsumsi bahan bakar spesifik (SFC) menjadi 28,38\%, serta memiliki harga energi rendah dari mesin bensin dengan selisihhingga 47,40\% ( $\mathrm{Y} \& \mathrm{R}, 2013$ ). Rasio kompresi yang lebih tinggi dapat digunakan dalam engine dan peringkat oktan LPG.

Performa daya dan torsi kendaraan berbahan bakar LPG yang mengalami penurunan dikarenakan LPG mempunyai nilai oktan yang lebih tinggi ( nilai oktan LPG 112) dari BBM sehingga diperlukan mesin dengan rasio kompresi yang tinggi karena suhu penyalaan otomatis yang lebih tinggi (Ravi et al., 2017). Dengan demikian penelitian ini bertujuan untuk melihat nilai daya dan torsi engine single piston dengan meningkatkan rasio kompresinya.

\section{METODE}

Penelitian ini dilakukan menggunakan sepeda motor berbahan bakar bensin, kemudian dimodifikasi menjadi berbahan bakar LPG ( spesifikasi sepeda motor disajikan pada tabel 1) dengan memasang sebuah vaporizer LPG untuk mereduksi tekanan dan mengubah fase LPG ke dalam fase gas. LPG yang digunakan adalah kemasan tabung $3 \mathrm{~kg}$ dengan regulator variabel. Di depan intake manifol dipasang sebuah tutup yang dilubangi yang berfungsi untuk mengurangi luas penampang intake manifold, sehingga menaikan kecepatan udara serta
(Setiyo \& Purnomo, 2014). Dengan sistem dan Selain itu, ini juga untuk menyesuaikan kebutuhan udara yang kurang dari penggunaan bensin karena kandungan karbon LPG lebih rendah dari teknologi mesin yang lebih maju, penurunan daya dapat direduksi menjadi $5 \%$ $10 \%$.

menurunkan tekanan masuk. bensin (Setiyo et al., 2016).

Skema modifikasi karburator disajikan dalam gambar 1 berikut. Pengujian dilakukan

dengan variasi tekanan kompresi dari 9 Bar (standar), 9,5 Bar dan 10 Bar. Gambar 2 memperlihatkan skema pengujian performa mesin single piston menggunakan dynotest dengan type REXTOR PRO DYNO, adapun spesifikasi mesin single piston (Tabel 1).

\section{HASIL DAN PEMBAHASAN PENELITIAN}

Gambar 3 menunjukan hasil pengujian torsi mesin 4 langkah single piston dengan bahan bakar LPG dan bensin dengan variabel tekanan rasio 9 Bar, 9,5 Bar dan 10 Bar. Torsi maksimum sebesar $12,07 \mathrm{Nm}$ pada putaran engine $4052 \mathrm{rpm}$ dicapai dengan menggunakan BBM. Sedangkan untuk penggunaan BBG, Tekanan kompresi 9 Bar menghasilkan torsi sebesar 9,77 Nm pada $3380 \mathrm{rpm}$. Tekanan kompresi 9,5 Bar menghasilkan torsi sebesar 10,67 Nm pada $3820 \mathrm{rpm}$, dan tekanan kompresi 10 Bar menghasilkan torsi sebesar 10,79 $\mathrm{Nm}$ pada $3689 \mathrm{rpm}$.

Nilai torsi mesin akan meningkat seiring dengan meningkatnya tekanan rasio. Meningkatnya tekanan dalam ruang bakar akan meningkatkan temperatur campuran bahan bakar dan udara sehingga proses pembakaran di ruang bakar lebih sempurna. Dengan demikian energy yang dibangkitkan akan meningkat yang akibatnya Torsi akan ikut meningkat.

TABEL 1. Spesifikasi mesin

\begin{tabular}{ll}
\hline No & \multicolumn{1}{c}{ Item } \\
\hline 1. Mesin & $:$ Spesifikasi \\
2. Sistem pendingin & $:$ langkah, SOHC \\
3. Jumlah silinder & $:$ Tunggal, mendatar \\
4. Isi silinder & $: 124,9 \mathrm{cc}$ \\
5. System bahan bakar & $: 52,4 \times 57,9 \mathrm{~mm}$ \\
6. Diameter x langkah (bore $x$ stroke) & $: 9,0: 1$ \\
7. Rasio kompresi & $: 9,3$ PS pada 7500 rpm \\
8. Power maksimal & $: 10,1$ Nm pada 4000 rpm \\
9. Torsi maksimal & $:$ Kopling ganda, otomatis sentrifugal, tipe basah \\
10. Kopling & $:$ Manual, 4 kecepatan \\
11. Transmisi & $: 3,7$ liter \\
12. Kapasitas tangki &
\end{tabular}




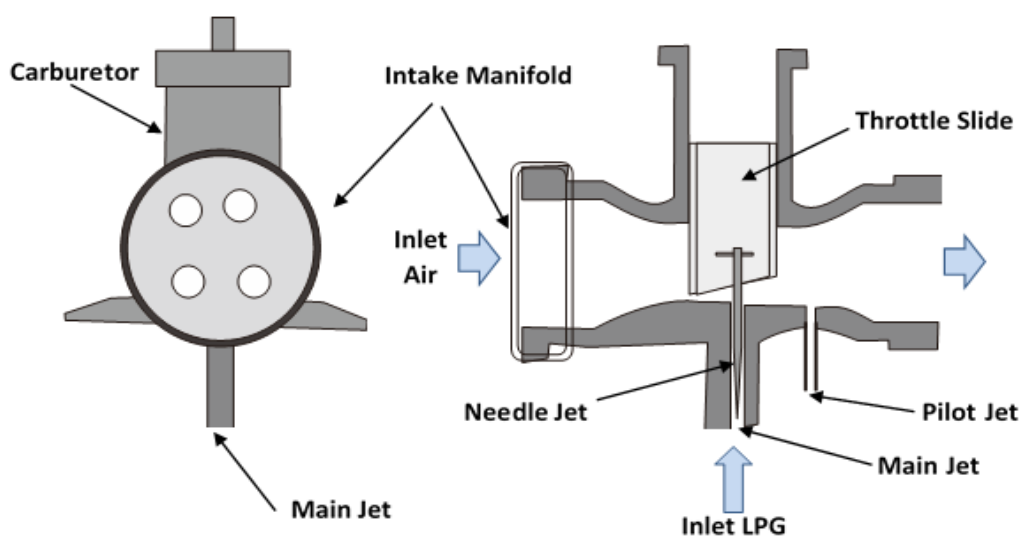

GAMBAR 1. Skema modifikasi Karburator

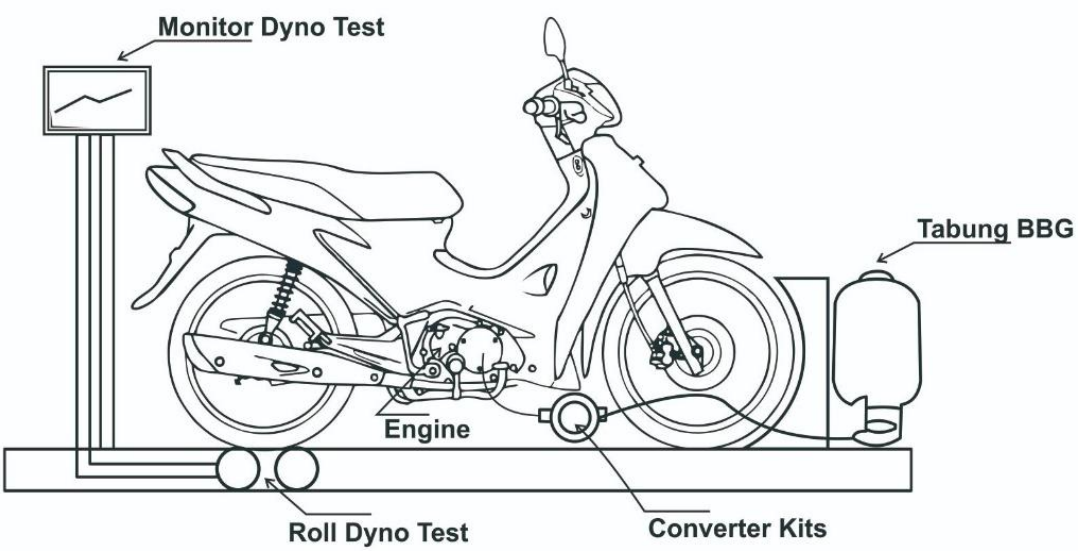

GAMBAR 2. Skema pengujian kendaran

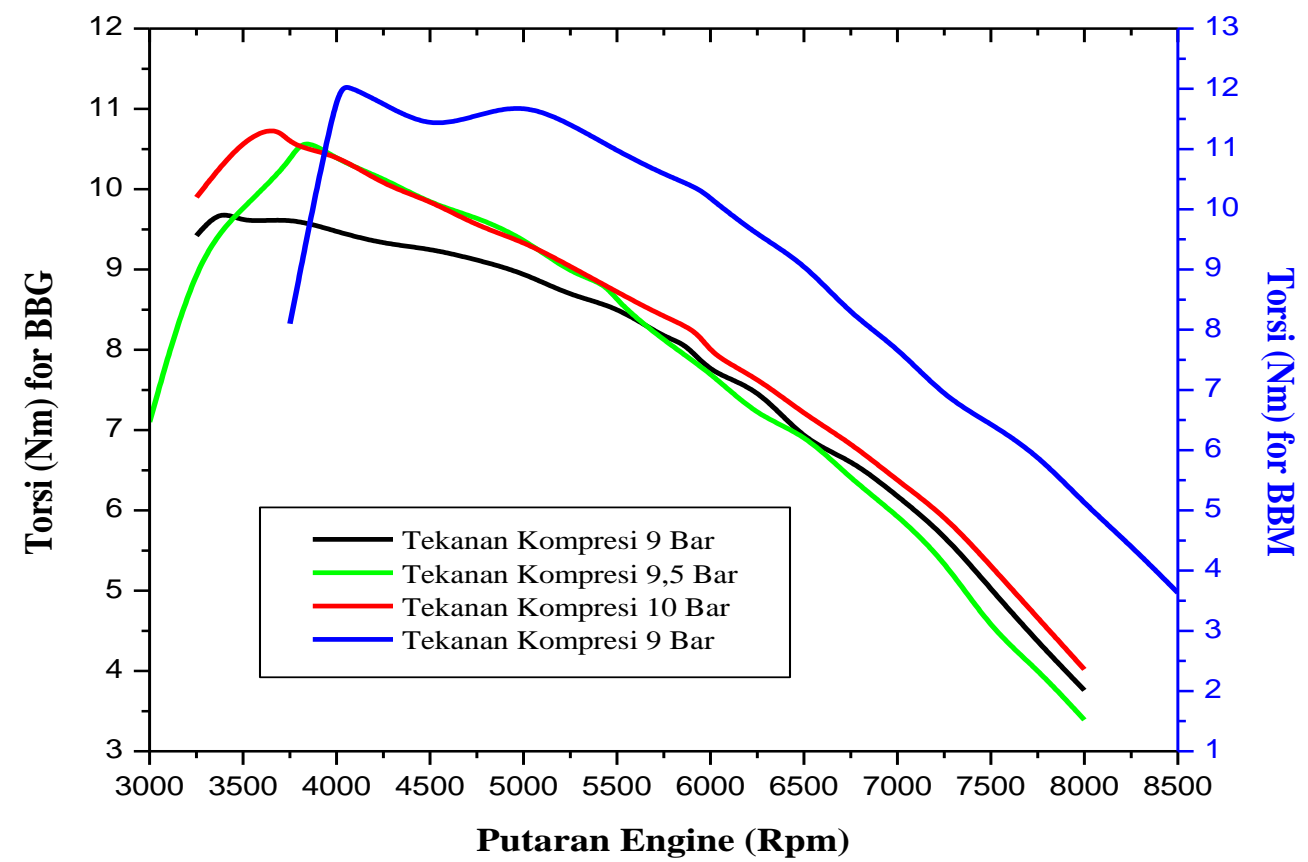

GAMBAR 3. Torsi terhadap putaran mesin (LPG variasi tek. 9, 9,5, 10 bar dan BBG tek 9 bar) 


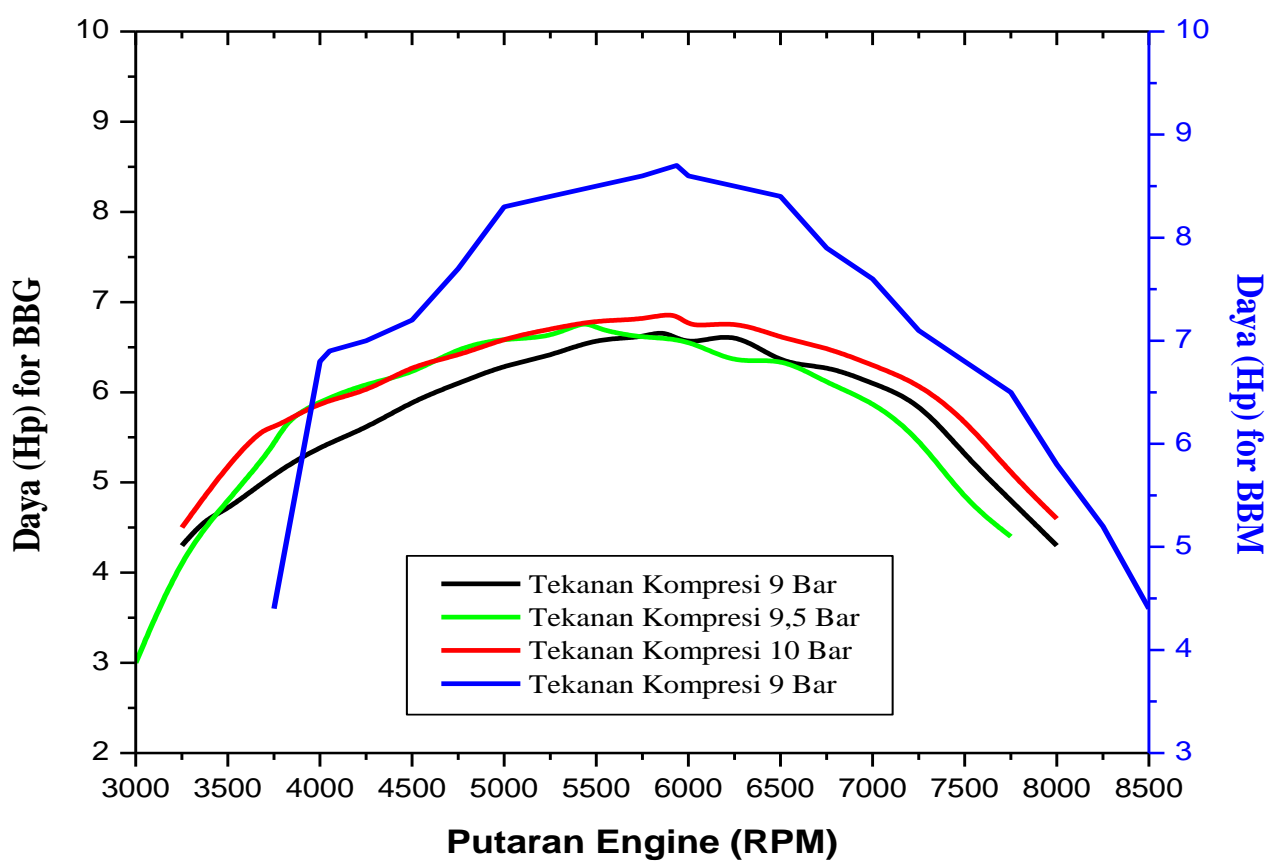

GAMBAR 4. Daya terhadap putaran mesin (LPG variasi tek. 9, 9,5, 10 bar dan BBG tek. 9 bar)

Untuk mendapatkan torsi setara dengan bensin, perlu penambahan kompresi rasio yang lebih tinggi. Kompresi rasio yang akan memberikan peningkatan disbanding dengan BBM jika dilakukan diatas 10,5 : 1 (Ravi et al., 2017). Selain itu, penurunan torsi juga disebabkan oleh penurunan efisiensi volumetrik karena penutupan tanduk udara karburator, dan tekanan LPG dari tangki ke alat penguap yang terlalu kecil (kurang dari 2 bar). Seharusnya, penelitian ini menggunakan kopling LPG sehingga tekanan di pipa LPG ke vaporizer sama dengan tekanan LPG di tabung.

Gambar 4 menunjukan hasil pengujian daya mesin 4 langkah single piston dengan bahan bakar LPG dan bensin dengan variabel tekanan rasio 9 Bar, 9,5 Bar dan 10 Bar. Daya maksimum yang dicapai untuk BBM sebesar 8,7 HP untuk tekanan kompresi 9 Bar pada putaran engine $5936 \mathrm{rpm}$. Sedangkan untuk penggunaan $\mathrm{BBG}$, daya maksimum sebesar 6,7

Hp pada rpm 5870 pada tekanan kompresi 9 Bar. Untuk tekanan kompresi 9,5 Bar menghasilkan daya maksimum sebesar $6,8 \mathrm{Hp}$ pada $5436 \mathrm{rpm}$, sedangkan untuk tekanan kompresi 10 Bar menghasilkan daya maksimum sebesar 6,9 Hp pada 5936 rpm.

Nilai daya mesin akan meningkat seiring dengan meningkatnya tekanan rasio. Namun daya maksimum mesin dengan LPG lebih rendah daripada bensin, dengan alasan yang sama untuk torsi. Namun, pada putaran mesin rendah, penggunaan LPG cukup menjanjikan. Dapat dilihat bahwa kurva daya mulai meningkat pada $3.250 \mathrm{rpm}$, sedangkan dengan bensin, peningkatan kurva daya baru dimulai pada putaran mesin di atas $3500 \mathrm{rpm}$.

\section{KESIMPULAN}

Hasil pengujian torsi dan daya untuk mesin 4 langkah single piston dengan bahan bakar LPG menghasilkan nilai yang meningkat seiring dengan penambahan tekanan kompresi. Nilai torsi tertingi untuk bahan bakar LPG adalah $10,79 \mathrm{Nm}$ yang dicapai pada putaran mesin 3689 rpm dengan tekan kompresi 10 Bar. Sedangkan nilai daya tertinggi untuk bahan bakar LPG adalah 6,9 HP yang dicapai pada putaran mesin $5936 \mathrm{rpm}$ dengan tekan

kompresi 10 Bar. Namun, torsi mesin dan tenaga mesin LPG menurut penelitian ini masih di bawah bensin karena keterbatasan tekana kompresi yang harus lebih besar dari 10,5 Bar. Faktor lain adalah efisiensi volumetrik karena penutupan tanduk udara karburator dan tekanan LPG di saluran bahan bakar terlalu kecil (kurang dari 2 bar). 


\section{UCAPAN TERIMA KASIH}

Artikel ini merupakan bagian dari proyek pengembangan kendaraan berbahan bakar LPG di Laboratorium Otomotif Universitas Muhammadiyah Magelang. Oleh karena itu, diucapkan terimakasih kepada teknisi dan mahasiswa yang telah terlibat dalam proyek pengembangan ini.

\section{DAFTAR PUSTAKA}

Ashok, B., Ashok, S. D., \& Kumar, C. R. (2015). ORIGINAL ARTICLE LPG diesel dual fuel engine - A critical review. Alexandria Engineering Journal, 54(2), $105-126$ https://doi.org/10.1016/j.aej.2015.03.002

Bayraktar, H., \& Durgun, O. (2005). Investigating the effects of LPG on spark ignition engine combustion and performance, 46, 2317-2333. https://doi.org/10.1016/j.enconman.2004. 09.012

Ceviz, M. A. Ã., \& Yu, F. (2006). Cyclic variations on LPG and gasoline-fuelled lean burn SI engine, 31, 1950-1960. https://doi.org/10.1016/j.renene.2005.09. 016

ETSAP. (2010). Automotive LPG and Natural Gas Engines. (C) IEA ETSAP - Technology Brief T03, (April), 1-5.

Pourkhesalian, A. M., Shamekhi, A. H., \& Salimi, F. (2010). Alternative fuel and gasoline in an SI engine: A comparative study of performance and emissions characteristics. Fuel, 89(5), 1056-1063. https://doi.org/10.1016/j.fuel.2009.11.025

Pradesh-india, A., \& Pradesh-india, A. (2008). Performance and Emission Characteristics of LPG-Fuelled Variable Compression Ratio SI Engine, 32, 7-12.

Purnomo, B. C., Widodo, N., Munahar, S., Setiyo, M., \& Waluyo, B. (2017). Karakteristik Emisi Gas Buang Kendaraan Berbahan Bakar LPG untuk Mesin Bensin Single Piston (pp. 7-12).

Ravi, K., Bhasker, J. P., \& Porpatham, E. (2017). Effect of compression ratio and hydrogen addition on part throttle performance of a LPG fuelled lean burn spark ignition engine. Fuel, 205, 71-79. https://doi.org/10.1016/j.fuel.2017.05.062

Saraf, R. R., Thipse, S. S., \& Saxena, P. K. (2009). Comparative Emission Analysis of Gasoline / LPG Automotive Bifuel Engine, 3(3), 279-282.

Setiyo, M., \& Purnomo, B. C. (2014). Investigasi Penurunan Daya Mobil Berbahan Bakar Lpg Melalui Pengukuran Efisiensi Volumetrik. Seminar Nasional Sains dan Teknologi (p. ). Jakarta: FTUniversitas Muhammadiyah Jakarta.

Setiyo, M., Waluyo, B., Husni, M., \& Karmiadji, D. W. (2016). Characteristics of 1500 CC LPG fueled engine at various of mixer venturi area applied on Tesla A100 LPG vaporizer. Jurnal Teknologi. https://doi.org/10.11113/jt.v78.7661

Y, M., \& R, M. (2013). Performance of Single Cylinder Spark Ignition Engine Fueled by LPG. Procedia Engineering, 53, 579585.

https://doi.org/10.1016/j.proeng.2013.02. 074 